\title{
ОПТИМИЗАЦИЯ РЕЖИМА ПАССИВНОГО ЗАМОРАЖИВАНИЯ ПРИ ПРОХОДКЕ ШАХТНЫХ СТВОЛОВ ПОД ЗАЩИТОЙ ЛЕДОПОРОДНЫХ ОГРАЖДЕНИЙ
}

\author{
А.В. ПУГИН \\ Горный институт УрО РАН, г. Пермь
}

\begin{abstract}
Аннотация: В статье предлагается способ оптимизации режима работы замораживающей станции на этапе пассивного замораживания горных пород при проходке шахтных стволов в водонасыщенных осадочных породах под защитой ледопородного ограждения. Установлено, что при сохранении режима течения хладоносителя в замораживающих колонках преимущественное влияние на температурное поле в окружающем ствол массиве горных пород оказывает температура хладоносителя. Предлагается концептуальная постановка задачи оптимизации температуры хладоносителя при поддержании ледопородного ограждения в рабочем состоянии длительное время. Реализован алгоритм нахождения функции оптимального изменения температуры хладоносителя со временем и построены графики данной функции для трех типовых литологических разностей Петриковского ГОК. Предлагается рассчитывать аналогичные функции для типовых разностей участка строительства стволов в каждых конкретных условиях, отличных от условий площадки Петриковского ГОК. Дальнейшая оптимизация режима пассивного замораживания при производстве работ выполняется путем корректировки температуры хладоносителя в соответствии с показаниями оптоволоконной системы термометрического контроля ледопородного ограждения.
\end{abstract}

Ключевые слова: искусственное замораживание пород; ледопородное ограждение; проходка стволов; режим замораживания; оптимизация.

Искусственное замораживание горных пород является одним из основных способов создания временной защиты строящегося в водонасыщенных породах ствола проникновения подземных вод. Превращаясь в лед, вода прочно скрепляет частицы рыхлой породы, формирует водонепроницаемое ледопородное ограждение (ЛПО) вокруг будущей выработки и придает устойчивость ее стенкам. Поскольку существует несколько модификаций способа искусственного замораживания, следует оговорить, что в данной статье речь пойдет лишь о рассольном способе с применением рециркуляционных систем закрытого типа, не касаясь низкотемпературного замораживания, например, основанного на прямой подаче в массив жидкого азота.

Способ искусственного замораживания является довольно дорогостоящим. Основным видом затрат, которые обычно стараются оптимизировать, являются затраты электроэнергии при работе замораживающего комплекса [1,2]. Для более ясного понимания необходимо прежде всего рассмотреть основные элементы системы и этапы процесса искусственного замораживания.

Система замораживания закрытого типа имеет в составе холодильное и насосное оборудование, подключенное в замкнутую сеть трубопроводов с циркулирующим хладоносителем. В качестве хладоносителя обычно используются водные растворы солей (рассолы), чаще всего раствор хлорида кальция $\left(\mathrm{CaCl}_{2}\right)$. Холодильное оборудование обеспечивает охлаждение хладоносителя до отрицательной температуры, а насосное создает перепад давления для его циркуляции в замкнутом контуре трубопроводов - по магистральному трубопроводу прямого потока от холодильного оборудования к замораживающим колонкам, внутри замораживающих колонок для отбора теплоты от массива и далее к магистральному трубопроводу обратного потока, обеспечивая возврат к холодильному оборудованию.

Как временная защита, в значительной степени подверженная влиянию естественных и техногенных факторов, ЛПО нуждается в постоянном контроле в 
течение всего периода существования. Основным методом контроля состояния ЛПО является термометрический контроль. В современном исполнении этот метод реализуется при помощи оптоволоконных измерений температуры в специально подготовленных термометрических скважинах, пробуренных на удалении нескольких метров от контура проходки ствола и контура замораживающих колонок.

В процессе эксплуатации ЛПО различают три стадии его существования:

1) Активное замораживание - режим быстрого формирования ЛПО, который длится с начала замораживания и до достижения необходимой температуры породы и проектной толщины ЛПО;

2) Пассивное замораживание - режим поддержания ЛПО в течение всего периода, пока продолжается проходка ствола в интервале замороженных пород;

3) Размораживание (активное или пассивное) - искусственное или естественное размораживание массива вокруг шахтного ствола после его проходки и возведения постоянной водонепроницаемой крепи.

Задачи каждого этапа различны. Режим активного замораживания призван сформировать ЛПО требуемой прочности в расчетные сроки, соотнесенные с общим графиком ведения строительных работ. Прочность ЛПО в зависимости от характеристик породы определяется двумя факторами: его температурой и толщиной. Оборудование для замораживающего комплекса и режим его работы на данном этапе выбираются таким образом, чтобы выполнить поставленную задачу при минимальных энергетических и финансовых затратах.

Режим пассивного замораживания направлен на поддержание рабочего состояния ЛПО в течение всего периода эксплуатации. Если затраты на активное замораживание достаточно просто оптимизировать на этапе проектирования работ, то выбор оптимального режима поддержания ЛПО представляет собой весьма нетривиальную задачу.

Обычно поддержание ЛПО в рабочем состоянии не требует дальнейшего увеличения его толщины вовне и внутрь контура проходки ствола. В редких случаях, при применении комбайнового комплекса с пневматической системой транспортировки отбитой породы требуется промерзание массива во всем контуре проходки. В режиме пассивного замораживания задача снижения эксплуатационных затрат сводится к уменьшению холодопроизводительности замораживающего комплекса до уровня, способного скомпенсировать внешние и внутренние теплопритоки, минимизируя при этом рост ограждения. Уменьшение холодопроизводительности регулируют повышением температуры и/или снижением расхода циркулирующего хладоносителя.

Неконтролируемое снижение холодопроизводительности, не опирающееся на данные температурного мониторинга породного массива и инженерные расчеты, в лучшем случае не позволяет оптимизировать энергозатраты, а в худшем - способно привести к потере прочности ЛПО и разрушению стенок ствола.

Опираясь на опыт одновременных наблюдений за состоянием шести ледопородных ограждений строящихся стволов, специалистами «ГИ УрО РАН» разработана методика оптимального управления работой замораживающего комплекса в режиме поддержания заданной толщины ЛПО. Данная методика содержит в основе алгоритм, позволяющий рассчитать наилучший по критерию энергозатрат режим регулирования температурного состояния ЛПО с учетом внешних (земных) и внутренних (со стороны ствола) теплопритоков, которые возможно оценить по данным экспериментальных измерений.

В процессе предварительных исследований установлено следующее: 
1) в подавляющем большинстве случаев движение хладоносителя в замораживающих колонках соответствует ламинарному либо переходному режиму;

2) без резкого (скачкообразного) изменения режима течения способность хладоносителя отводить теплоту от массива преимущественно определяется его температурой, а не расходом., а следовательно, регулируемым параметром должна являться именно температура.

Разработанный алгоритм позволяет рассчитать функцию оптимального повышения температуры хладоносителя $T_{c}=T_{c}(t)$, где $t$ - время, отсчитываемое с момента достижения требуемой толщины ЛПО во всем интервале замораживания пород. При производстве работ требуется лишь отрегулировать параметры замораживающего комплекса в соответствии с этой функцией.

Концептуальную постановку задачи нахождения функции $T_{c}$ рассмотрим на примере одного слоя горной породы, подвергнутого замораживанию:

1) пусть распределение температуры в слое в каждый момент времени $t$ определяется решением двумерной обратной задачи Стефана в горизонтальной плоскости $X O Y$ и может быть восстановлено по данным температурного мониторинга [3, 4];

2) после полного смыкания ЛПО определим изотермы границ ЛПО: внутренней $T_{1}(x, y)=$ Const и внешней $T_{2}(x, y)=$ Const при условии равенства температур $T_{1}=$ $T_{2}$ - температура прочного ЛПО согласно проекту на замораживание пород;

3) в любой момент времени $t$ условимся считать толщиной ЛПО величину $h=\min d\left(T_{1}, T_{2}\right)$, то есть минимальное расстояние между выбранными изотермами в горизонтальной плоскости $X O Y$;

4) в момент времени $t_{0}$ достижения требуемой толщины ЛПО $h=\min d\left(T_{1}, T_{2}\right)$ определим положение изотерм $T_{1}(x, y)$ и $T_{2}(x, y)$.

5) внешние теплопритоки к границам ЛПО постоянны, внутренние (со стороны ствола) - либо постоянны, либо задаются известным законом; температура хладоносителя может изменяться во времени, но остальные параметры математической модели (в том числе и расход хладоносителя), отвечающие за температурное поле, остаются неизменными;

6) требуется найти такой закон повышения температуры хладоносителя $T_{c}=T_{c}(t)$, чтобы достигнутая толщина $h_{0}=\min d\left(T_{1}, T_{2}\right)$ оставалась неизменной, иначе говоря, чтобы положение изотерм $T_{1}$ и $T_{2}$ не менялось.

Описанная в пп.1-6 задача может иметь решение только в условиях одного слоя и полной вращательной симметрии относительно оси будущего ствола. В реальности строгие требования п.6 смягчаются до определения функции $T_{c}(t)$ такой, чтобы увеличение толщины ЛПО $h$ со временем было минимальным. Уменьшение толщины ЛПО ниже значения $h_{0}$ не в принципе не допустимо.

Алгоритм решения задачи оптимизации разработан в численном виде первоначально в одномерной постановке с нахождением оптимальной функции теплового потока $q=q(t)$ на внешней границе одной замораживающей колонки. Функция $q$ является результатом решения обратной задачи Стефана и в дальнейшем пересчитывается в функцию температуры $T_{c}$. Впоследствии алгоритм был доработан на случай полной двумерной постановки.

Апробация алгоритма проведена применительно к задаче мониторинга состояния ЛПО на участке строительства шахтных стволов Петриковского ГОК (Республика Беларусь). В ходе выполнения работ определены три типовые литологические разности горных пород (песок, мел и глина), принципиально отличающиеся минеральным и гранулометрическим составом, физико-механическими и теплофизическими 
свойствами. Для указанных разностей выбраны наиболее типичные значения теплофизических характеристик и решена рассмотренная выше задача оптимизации.

Распределение температуры на момент достижение требуемой толщины ЛПО в каждом слое определялось режимом активного замораживания. Исследовались два предельных случая, позволяющие получить оценку сверху и снизу: в одном из них рабочая температура хладоносителя при активном замораживании принималась равной $-20 \square \mathrm{C}$, во-втором - $-35 \square \mathrm{C}$. Выход на рабочую температуру осуществлялся постепенным понижением согласно нормативу (не более чем на $3{ }^{\circ} \mathrm{C} /$ сутки). В результате расчетов построены кривые оптимального повышения теплового потока $q$ и температуры $T_{c}$, представленные на рисунке ниже.
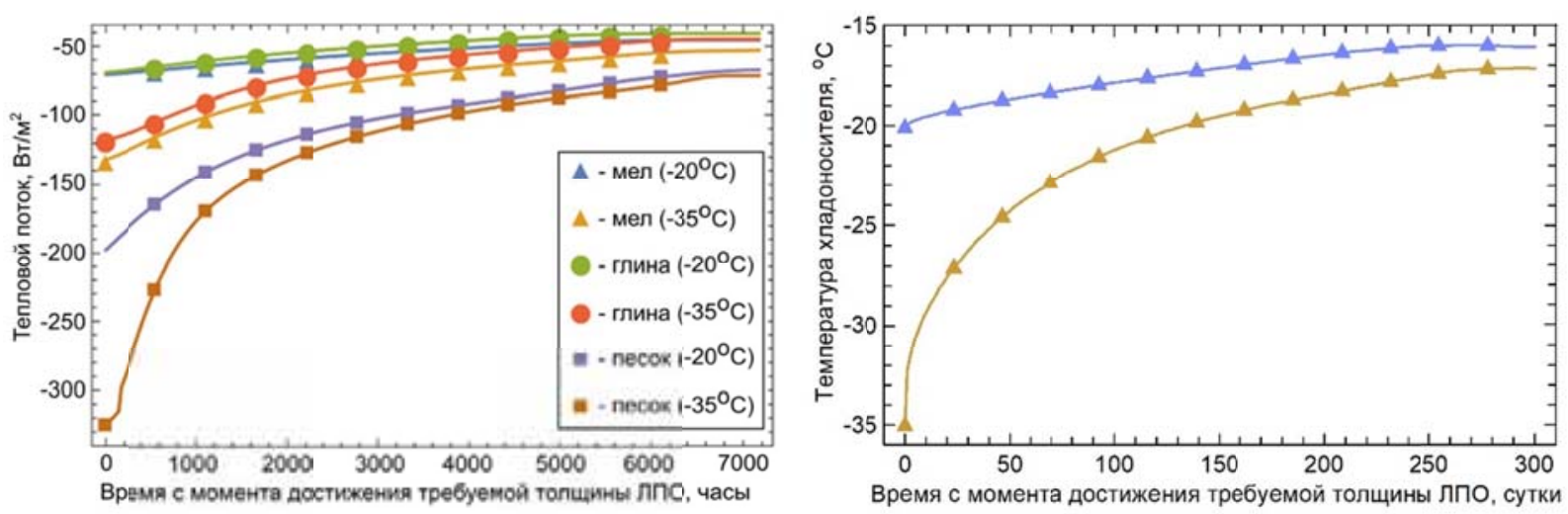

Рис. 1. Графики оптимального повышения теплового потока на внешней стенке замораживающей колонки для трех типовых литологических разностей (слева) и температуры хладоносителя для мела (справа)

Вследствие различий физических характеристик породы по-разному реагируют на изменение температуры хладоносителя. Из указанных литологических разностей наиболее плавного повышения температуры требует мел. Если рассматривать весь разрез в целом и при оптимизации режима ориентироваться на мел, то в других слоях ледопородное ограждение будет продолжать увеличиваться в размерах. В то же время повышение температуры в соответствии с графиком для глин или песка приведет к уменьшению толщины ЛПО в слое мела ниже требуемого по проекту значения. Следовательно, режим с повышением температуры «по мелу» является единственно возможным для сохранения требуемой толщины ЛПО во всех без исключения слоях в интервале замораживания пород. На основании результатов численного моделирования можно сделать вывод: порода, обладающая наименьшей температуропроводностью и наибольшим влагосодержанием, является определяющей при выборе оптимального режима повышения температуры хладоносителя.

По результатам исследования разработаны рекомендации, которые вошли в Инструкцию по расчету, контролю и управлению искусственным замораживанием горных пород при строительстве шахтных стволов на калийных рудника ОАО «Беларуськалий». На практике при наличии в разрезе литологических разностей, обладающих сходным составом, физико-механическими и теплофизическими характеристиками, возможно использование ранее полученных кривых повышения температуры хладоносителя. В принципиально отличающемся разрезе должно быть выполнено построение аналогичной функции $T_{c}(t)$ применительно к имеющимся породам.

При управлении режимом замораживающей станции в соответствии с функцией температуры $T_{c}(t)$ возможны отклонения от расчетного поведения ЛПО. 
Предполагается, что математическая модель учитывает основные факторы, влияющие на распределение температур в массиве, и ожидаемые отклонения не должны быть значительными. В этом случае работа замораживающего комплекса должна быть отрегулирована (тонкая корректировка режима) в каждом конкретном случае по показаниям системы термометрического контроля и данным ежесуточных расчетов.

Работа выполнена при поддержке гранта по конкурсу фундаментальных исследований Уральского отделения Российской академии наук (проект № 18-5-5-5).

\section{БИБЛИОГРАФИЧЕСКИЙ СПИСОК}

1. Головатый И.И., Левин Л.Ю., Паршаков О.С., Диулин Д.А. Оптимизация процессов формирования ледопородного ограждения при сооружении шахтных стволов // Горн. журн. - 2018. - № 8. - С. 48-53. DOI: $10.17580 / \mathrm{gzh} .2018 .08 .06$.

2. Alzoubi M.A., Sasmito A.P., Madiseh A., Hassani F.P.. Freezing on demand (FOD): An energy saving technique for artificial ground freezing // Energy Procedia. - 2019. - V. 158. - P. 4992-4997. DOI: 10.1016/j.egypro.2019.01.667.

3. Levin L.Y., Semin M.A., Zaitsev A.V. Solution of an inverse Stefan Problem in Analyzing the Freezing of Groundwater in a Rock Mass // Journal of Engineering Physics and Thermophysics. - 2018. - V. 91, № 3. P. 611-618. DOI: 10.1007/s10891-018-1782-3.

4. Левин Л.Ю., Зайцев А.В., Семин М.А. Контроль теплового режима породного массива на основе применения оптоволоконных технологий мониторинга температур в скважинах // Горное эхо. - 2016. - № 1 (62). - C. 35-37. 